\title{
Assessing Agricultural Potential in South Sudan - A Spatial Analysis Method
}

\author{
Xinshen Diao, Liangzhi You, Vida Alpuerto and Renato Folledo
}

Additional information is available at the end of the chapter

http://dx.doi.org/10.5772/47938

\section{Introduction}

After almost five decades of war and armed conflict, South Sudan achieved its independence in July 2011. Expectations are high that the independence will bring peace, food security, improved health, and prosperity to its people. The world's newest nation, South Sudan is naturally endowed with agricultural potential given its favourable soil, water, and climatic conditions. It is estimated that about 70 percent of total land area is suitable for producing a wide range of agricultural products, including annual crops such as grains, vegetables, tree crops such as coffee, tea, and fruits, livestock, fishery, and various forest products. To realize such agricultural potential and achieve economic development and broad-based improvements in the nation's living standards, a realistic understanding of the country's initial conditions is required such that appropriate policy measures and agricultural growth strategy can be designed in the near future.

This chapter focuses on analyzing a more realistic agricultural potential in South Sudan in five to ten year horizon. While such analysis seems to be straightforward in most other countries, it is a monumental task in South Sudan given its protracted history of violence. A functional government statistics system that regularly collects socio-economic data literally did not exist during the turmoil years. Hence, our analysis needed to put together different spatial data from several available sources. The key GIS datasets that we used are the 2009 Land Cover data which provides land use information for South Sudan, the Oak Ridge National Laboratory's 2001 LandScan population data, and the most recently updated road condition surveys conducted by World Food Program (WFP). We combine these GIS datasets with the 2008 population census and 2009 National Baseline Household Survey (NBHS) carried out by the country's National Bureau of Statistics (formerly known as Southern Sudan Centre for Census, Statistics and Evaluation). While the agricultural potential is analyzed spatially, the socio-economic datasets, which are both nationally 
representative, allow the statistical analysis to be carried out at subnational levels such as at the state and livelihood zone levels.

In the next section, we estimate the size and distribution of the different types of land use, as well as the association between agricultural potential and population density in South Sudan. Based on the agricultural consumption and production patterns, the current agricultural values in monetary terms are calculated in Section 3. In the same section, we then estimate the agricultural potential value in the next five to ten years by simulating an increase in cultivated area though cropland expansion and improvements in agricultural productivity. Section 4 concludes.

\section{Spatial distribution of different types of land use}

The country's current land use and coverage in the different states ${ }^{1}$ and livelihood zones ${ }^{2}$ is described in this section. Then, we use the length of growing period (LGP) ${ }^{3}$ as proxy for determining typologies of agricultural production potential and describe the relationship between such potential and population density.

\section{Current land use}

We use a two-step process to derive South Sudan's land use from almost 300 types based on Land Cover data obtained from FAO in 2009. First, the land use types were resampled and aggregated into 18 classes as depicted in Map 1. In the second step, we further aggregated the land use types into 8 categories (Table 1). For agricultural production potential, we use LGP equal to or more than 180 days as an indicator for sufficient moisture and temperature conditions that permit crop growth. Using this threshold, about 80 percent of the country's territory is under climatic conditions that are considered suitable for agriculture. However, the aggregation of the land use types indicates that most of the land that is suitable for agriculture is still under natural vegetation. As shown in Table 1, land that is currently under crop cultivation, most of which are rainfed, accounts for less than 4 percent of total land. Conversely, the largest part of the country is still under trees and shrubs (62.6 percent). Given the country's favorable agricultural climate condition, this ratio is clearly very low as the crop areas account for more than 28 percent of national land in Kenya and 8 in Uganda. Before South Sudan became an independent country, crop areas in Sudan as a whole accounts for 7 percent of total land. Given that the agro-climate conditions are less favorable in the northern Sudan than that in South Sudan, it is obvious that South Sudan is

\footnotetext{
${ }^{1}$ South Sudan has ten states: Upper Nile, Jonglei, Unity, Warrap, Northern Bahr el Ghazal, Western Bahr el Ghazal, Lakes, Western Equatoria, Central Equatoria, and Eastern Equatoria.

2 The country is divided into seven livelihood zones that are identified under the country's livelihood profile project and defined based on climate conditions and farming systems (SSCCSE, 2006): Eastern Flood Plains, Greenbelt, Hills and Mountains, Ironstone Plateau, Nile-Sobat Rivers, Pastoral, and Western Flood Plains.

${ }^{3}$ The concept length of growing period is used in the Global Agro-Ecological Zone Project led by the International Institute for Applied Systems Analysis and the UN Food and Agriculture Organization. For more detailed information, see Fisher et al. (2002).
} 
significantly underdeveloped in agricultural production. While the large land areas under natural vegetation definitely indicate huge agricultural potential in the country, the challenges to develop them into agricultural land, including required large physical investments and difficulty in identifying suitable farming systems and crop patterns, are huge.

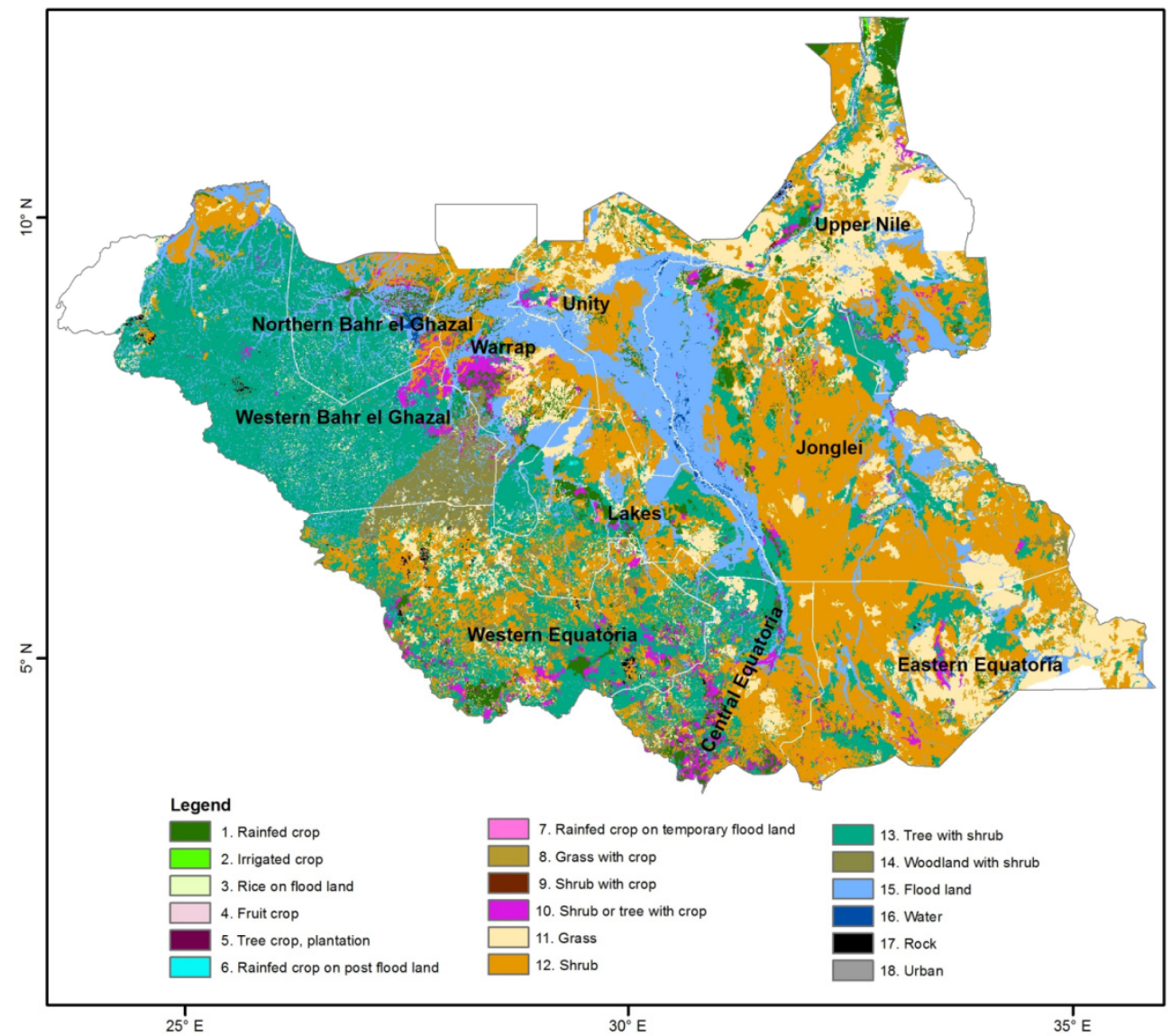

Source: Authors' aggregation using Land Cover database (FAO 2009).

Map 1. Spatial distribution of aggregated types of land use

We further consider the extent of land use types at both state and livelihood zone levels to understand its distribution (Map 2). In terms of cropland distribution, Western Flood Plains, which covers parts of Northern Bahr el Ghazal, Warrap, Unity and Lakes, is the most important livelihood zone, providing 34.2 percent of national cropland and 24.2 percent of national cropland mixed with grass and trees. Moreover, this zone has the highest ratio of cropland over total land, as cropland and cropland mixed with grasses/trees account for 8.5 and 5.4 percent of zonal territorial area, respectively. Greenbelt (spanning parts of Western 
Equatoria and Central Equatoria) and Eastern Flood Plains (encompassing Upper Nile and parts of Jonglei) are the two other major crop producing regions, accounting for respectively, 17.6 percent and 26.2 percent of national cropland, and 25.7 percent and 14.6 percent of the country's land mixed crops with grasses/trees. Both zones also have high ratio of cropland to total land as lands with crops and crops mixed with grasses/trees account for 11.4 percent of total land in Greenbelt and 6.8 percent of total land in Eastern Flood Plains. In total, these three agricultural zones provide 78 percent of national cropland and 64.6 percent of national cropland mixed with grass/tree, but only covers about 47 percent of national territorial area.

\begin{tabular}{|c|c|c|c|c|c|}
\hline & $\begin{array}{l}\text { Area } \\
\text { (in } 1000 \\
\text { ha) }\end{array}$ & $\begin{array}{l}\text { Share of } \\
\text { total land } \\
(\%)\end{array}$ & & $\begin{array}{l}\text { Area } \\
\text { (in } 1000 \\
\text { ha) }\end{array}$ & $\begin{array}{l}\text { Share of } \\
\text { total land } \\
(\%)\end{array}$ \\
\hline A: By 18 types of land use categories & & & B: By 8 aggregated categories & & \\
\hline Rainfed crop & $2,379.3$ & 3.7 & Cropland & $2,477.7$ & 3.8 \\
\hline Irrigated crop & 32.1 & 0.0 & Grass with crop & 325.1 & 0.5 \\
\hline Rice on flood land & 6.0 & 0.0 & Trees with crop & $1,707.3$ & 2.6 \\
\hline Fruit crop & 0.1 & 0.0 & Grass & $9,633.8$ & 14.9 \\
\hline Tree crop, plantation & 6.2 & 0.0 & Shrub and tree & $40,526.9$ & 62.6 \\
\hline Rainfed crop on post flood land & 25.4 & 0.0 & $\begin{array}{l}\text { Trees, shrubs and other } \\
\text { vegetation on flood land }\end{array}$ & $9,497.6$ & 14.7 \\
\hline Rainfed crop on temporary flood land & 28.5 & 0.0 & Water and rock & 482.7 & 0.7 \\
\hline Grass with crop & 325.1 & 0.5 & Urban & 37.0 & 0.1 \\
\hline Shrub with crop & 4.3 & 0.0 & Total & $64,688.3$ & 100.0 \\
\hline Shrub or tree with crop & $1,703.0$ & 2.6 & & & \\
\hline Grass & $9,633.8$ & 14.9 & & & \\
\hline Shrubs & $20,506.6$ & 31.7 & & & \\
\hline Tree with shrub & $17,694.9$ & 27.4 & & & \\
\hline Woodland with shrub & $2,325.4$ & 3.6 & & & \\
\hline $\begin{array}{l}\text { Tree, shrub, and other vegetation on } \\
\text { flood land }\end{array}$ & $9,497.6$ & 14.7 & & & \\
\hline Water & 350.1 & 0.5 & & & \\
\hline Rock & 132.6 & 0.2 & & & \\
\hline Urban & 37.0 & 0.1 & & & \\
\hline Total & $64,688.3$ & 100.0 & & & \\
\hline
\end{tabular}

Source: Authors' aggregation from 2009 Land Cover.

Table 1. Area and share of total land, by aggregated types of land use

\section{Agricultural potential and population density}

Based on the LGP classification, about 27.3 percent of cropland in South Sudan is located in areas with high agricultural potential (LGP of more than 220 days) and another 41.5 percent in the medium potential areas (LGP between 180 to 220 days) (Table 2). To some extent, population determines the current crop production, as well as fulfilling crop system's potential for intensive farming in the short to medium term. Roughly 34 percent and 46 percent of population lives in such areas of high and medium agricultural potential, respectively. 
The majority of South Sudanese (85 percent) lives in rural areas, which we classify into two categories: "low density" areas with population less than 10 per square kilometer $\left(10 / \mathrm{km}^{2}\right)$ and "medium to high density" areas with population above that threshold. With 13 people per $\mathrm{km}^{2}$, the average population density is very low in South Sudan compared to other countries in the region. The low average is driven by the fact that only 25 percent of the population lives in 83.4 percent of the total territorial lands in South Sudan (Table 2). Accordingly, the population density averages $4 / \mathrm{km}^{2}$ in these areas. In contrast, the remaining 75 percent of the population resides in "medium to high density" areas representing just 16.6 percent of country's total land, thereby resulting to density of $57 / \mathrm{km}^{2}$.We combine the LGP and population density categories that results in six agricultural potential typologies (Table 2; Map 3).

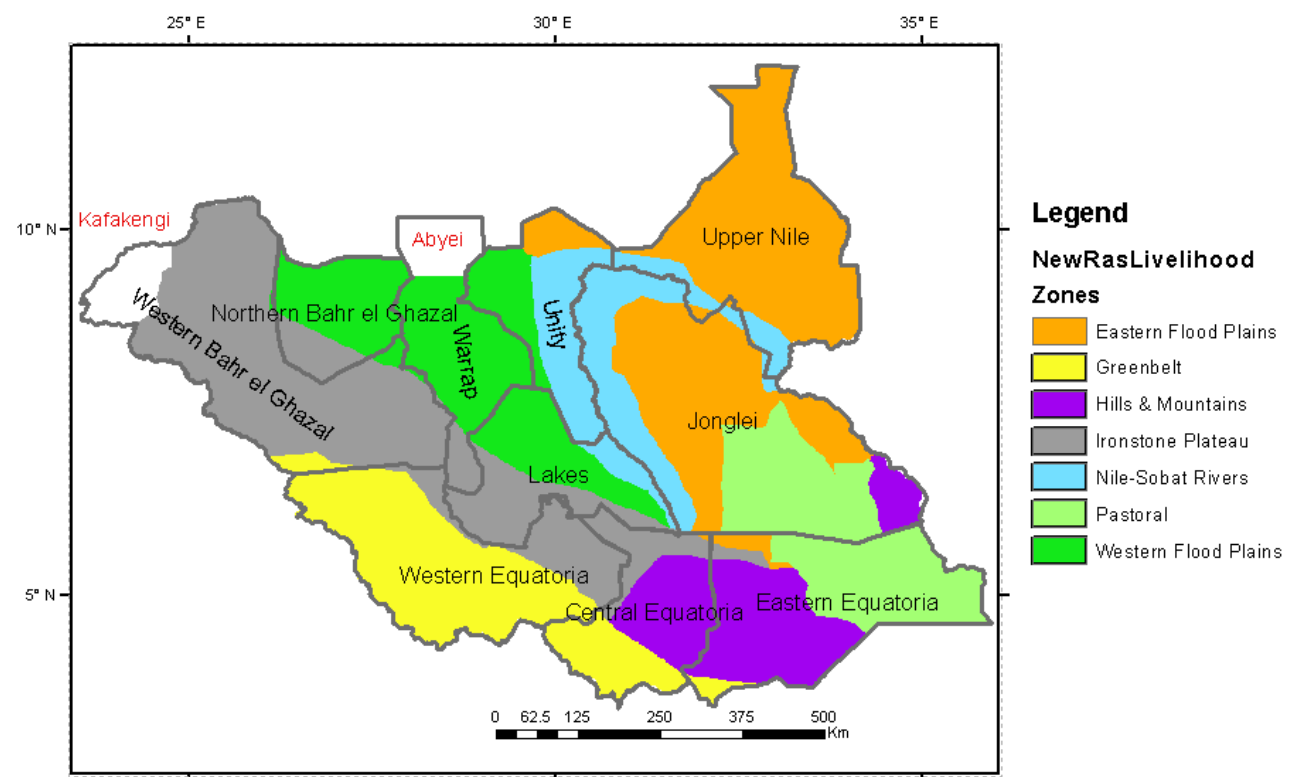

Source: Authors' estimates.

Map 2. The ten states and seven livelihood zones

Our analysis indicates that Type $\mathrm{HH}, \mathrm{HL}$, and $\mathrm{MH}$, which are the three typologies of high agricultural potential areas, collectively cover 54 percent of total crop land. This is mostly driven by large areas of $\mathrm{MH}$ in Warrap and Lakes representing 26.7 percent of total cropland area (Map 3). This is followed by Type HH (15.3 percent) which can be attributed to the similarly large areas of high population density-high agricultural potential in Western Equatoria and Central Equatoria. Among crop production zones, Greenbelt has the highest share of cropland distinguished as Type $\mathrm{HH}$, while Western Flood Plains dominates the $\mathrm{MH}$ category (Map 3). On the other hand, half of the cropland areas in the Eastern Flood Plains are characterized as LL primarily because of the large contribution of Upper Nile region that falls under this category. 


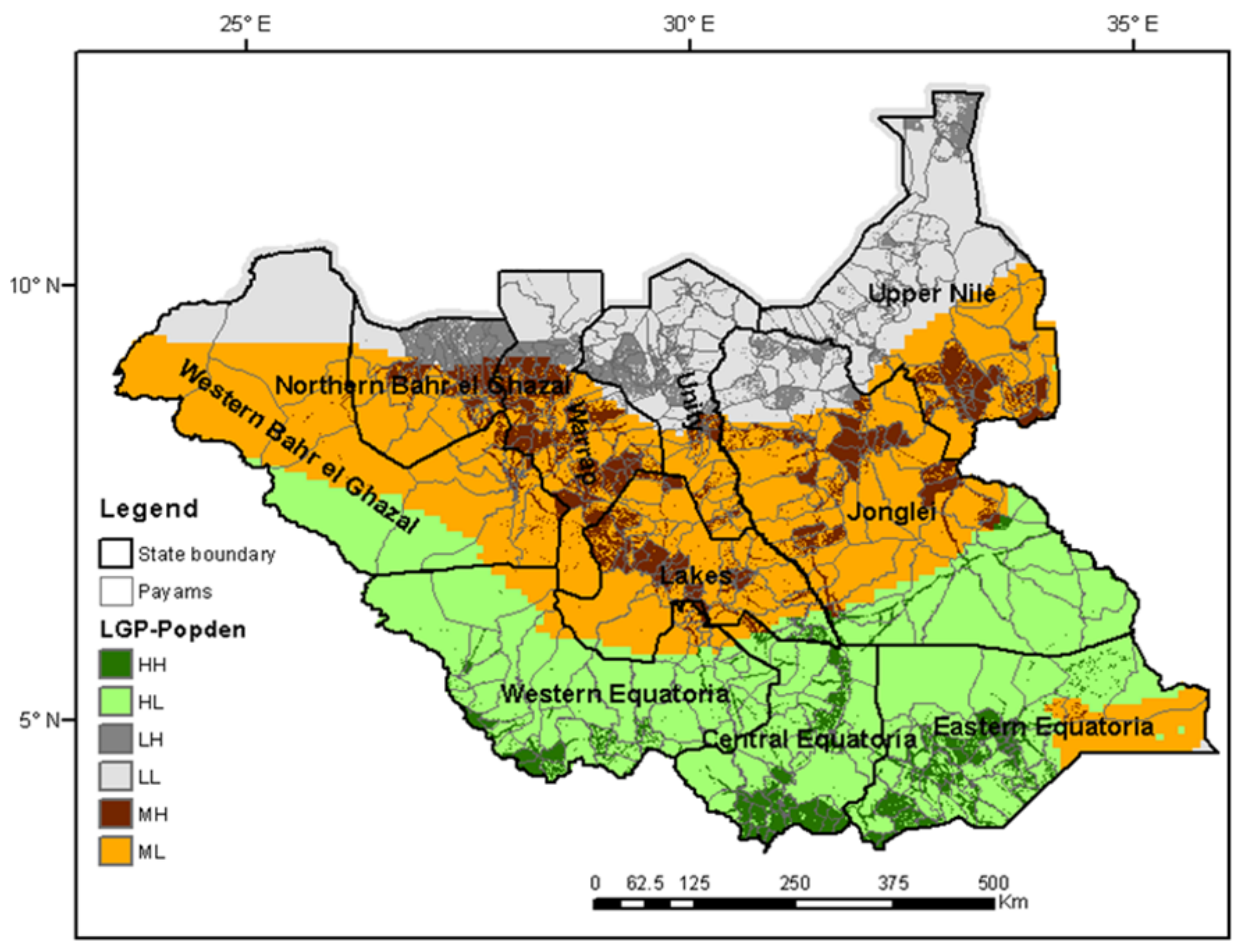

Source: Authors' estimates.

Note: HH: High agricultural potential/high-medium population density; HL: High agricultural potential/low population density; MH: Medium agricultural potential and high-medium population density; ML: Medium agricultural potential/low population density; LH: Low agricultural potential and high-medium population density; and LL: Low agricultural potential and low population density.

Map 3. Spatial patterns of agricultural potential and population density

The results also show that the potential for agricultural production and population density are spatially correlated. The areas classified as having "high" and "medium" potential have the highest population density at $66 / \mathrm{km}^{2}$ and $54 / \mathrm{km}^{2}$, respectively (Table 2). Both are greater than the $50 / \mathrm{km}^{2}$ threshold that is often used to identify the possibility for promoting intensive farming system in an area (Boserup1965; 1981). However, some areas in "high" potential Western and Central Equatoria that are parts of the Eastern Flood Plains have population densities that are low (e.g. these areas are Type HL). This indicates the difficulty of developing an intensive smallholder farming system even in areas with high agricultural potential. Moreover, because the cropland area under "high" potential is almost equally split between "medium to high" and "low" population density, the area of cropland at 0.18 hectare/per capita in the highest agricultural potential areas is extremely small compared with the national average of 0.30 ha/per capita. Nonetheless, among the six typologies, the ones that are best positioned to generate high returns from investments are $\mathrm{HH}, \mathrm{HL}$, and $\mathrm{MH}$. Given that more than half of the cropland areas fall under these categories, these areas should be prioritized for agricultural development programs. 


\begin{tabular}{|c|c|c|c|c|c|}
\hline & \multicolumn{4}{|c|}{ Agricultural potential defined by LGP } \\
\hline & & $\begin{array}{c}\text { High } \\
\text { LGP>220 } \\
\text { days }\end{array}$ & $\begin{array}{c}\text { Medium } \\
\text { 180-220 days }\end{array}$ & $\begin{array}{c}\text { Low } \\
<180 \text { days }\end{array}$ & Total \\
\hline \multirow{10}{*}{ 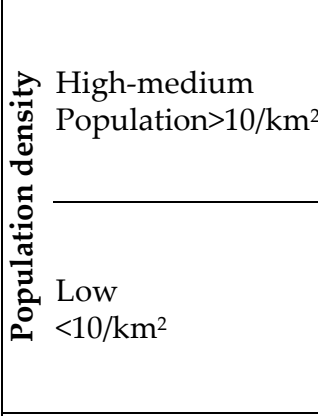 } & Population (\%) & 25.4 & 33.8 & 15.8 & 75.1 \\
\hline & Population density & 66 & 54 & 51 & 57 \\
\hline & Land $(\%)$ & 4.8 & 7.8 & 3.9 & 16.6 \\
\hline & Cropland area $(\%)$ & 15.3 & 26.7 & 17.9 & 59.9 \\
\hline & Cropland ha per capita & 0.18 & 0.23 & 0.33 & 0.24 \\
\hline & Population $(\%)$ & 8.7 & 11.9 & 4.4 & 24.9 \\
\hline & Population density & 3 & 4 & 3 & 4 \\
\hline & Land $(\%)$ & 31.5 & 35.2 & 16.7 & 83.4 \\
\hline & Cropland area (\%) & 12.0 & 14.9 & 13.2 & 40.1 \\
\hline & Cropland ha per capita & 0.41 & 0.37 & 0.89 & 0.48 \\
\hline \multirow{5}{*}{ Total } & Population (\%) & 34.1 & 45.7 & 20.2 & 100.0 \\
\hline & Population density & 12 & 13 & 12 & 13 \\
\hline & Land (\%) & 36.4 & 43.0 & 20.6 & 100.0 \\
\hline & Cropland area (\%) & 27.3 & 41.5 & 31.1 & 100.0 \\
\hline & Cropland ha per capita & 0.24 & 0.27 & 0.46 & 0.30 \\
\hline
\end{tabular}

Source: Authors' calculation based on 2001 LandScan and 2009 FAO Land Cover.

Table 2. Cropland, population, and population density according to agricultural potential

\section{Estimating agricultural potential}

\section{Realized agriculture potential}

Because of the country's diverse agro-ecological conditions, crops produced and consumed often differ spatially. With the absence of official agricultural production statistics in South Sudan and given that the agriculture system in the country is presently dominated by subsistence farming, we use the household food consumption data from the 2009 NBHS to estimate the current spatially disaggregated agricultural production. ${ }^{4}$ To be able to understand the country's agricultural potential, it is first necessary to derive a consistent measure of the current agricultural value for different locations, which we herein refer to as the "realized agriculture potential". The calculation considers both quantity of consumption

\footnotetext{
${ }^{4}$ With the exception of cereals, we assume that all agricultural products consumed in South Sudan are produced domestically. For these products, total consumption is assumed to equal domestic production; for cereals, we used a multi-step process because the country imports significant amounts of maize from Uganda and sorghum from Sudan. First, we convert cereal flour consumption into grain by assuming that $1 \mathrm{~kg}$ of flour is produced from $1.25 \mathrm{~kg}$ of raw grain. Second, following the assumption used by FAO/WFP, we approximate that post-harvest losses at 20 percent. Third, it is assumed that 55 percent of grain purchased by rural households is produced locally, while the rest is supplied by imports; for urban households, we assumed that purchases are mainly supported by imports. Finally, domestic grain production is defined as consumption met by households' own production, stocks, and 55 percent of total rural household's purchases.
} 
and production for 34 individual crops and the corresponding prices for them. The prices ${ }^{5}$ used in the calculation are averaged from individual households' self-reported information in the NBHS 2009. Limited by the lack of geo-referenced household identification in 2009 NBHS, we only calculate realized crop values at the state level.

The current value of crop production, which represents the "realized agriculture potential" in South Sudan, is only about US $\$ 600$ million. Crops, together with livestock and fishery products, make up about US $\$ 800$ million worth of total agricultural value, but still remains relatively low compared with that of neighbors. Given that the current cropland area is about 2.7 million ha, the average crop value per ha is US $\$ 227$.

Measured at household level, the total value is about $\$ 630$ per household, of which $\$ 470$ is from crops. The difference in per household agriculture value across states is large. For example, Western Equatoria, which has more lands allocated to high value crops, is the richest state with per household agricultural value close to US\$1,300. On the other hand, with less than US\$300, Unity, Northern Bahr Al Ghazal, and Western Bahr Al Ghazal have the lowest household agricultural values.

\section{Cropland expansion}

The low agricultural value can be mainly associated with South Sudan's undeveloped cultivated lands for agricultural production. As previously discussed, the country has abundant land with favorable climatic and soil conditions suitable for crop production; hence there is considerable scope that unutilized land can be converted into crop land under certain necessary conditions. Based on LGP, population density, and type of current land use, we project the potential cropland expansion under a moderate (Scenario 1) and a high expansion scenario (Scenario 2) in five and ten year horizons. In the previous section, we distinguished three types of crop-related land use: the areas identified as "cropland", areas as "grass with crops", and areas as "trees with crops" (Table 1). To start with a benchmark of current cropland area, we assume that 10 percent of areas defined as "grass with crops" and "trees with crops" have been cultivated and thus contributed to the current agricultural production. Hence, the benchmark cropland is the sum of land use under original crop land area $(24,779$ thousand ha; see Table 1$)$ plus 10 percent of land use each coming from "grass with crops" and "trees with crops". Based on this computation, it is estimated that cropland area is 2.7 million ha or 4.1 percent of total land area in the country (Table 3). However, areas under "grass with crops" are unlikely to become cropland due to unfavorable climatic and soil conditions. Thus, in the moderate expansion scenario, we adopt a hierarchical expansion model in which all land currently identified as "trees with crops" (2.6 percent of national land) is the first to be converted into cropland. Once this potential for expansion is exhausted, further expansion will occur in "tree land" areas (which currently accounts for

\footnotetext{
${ }^{5}$ If the state's average price for particular crop is extremely low or high relative to other states, the national average price is used. If the price is either not available from the survey or extremely low compared with that in neighboring countries, then the lowest relevant price from Kenya or Ethiopia is used.
} 
62.6 percent of national territory). For simplicity, we hereafter refer to both "trees with crops" and "tree land" as just "tree land" and use the following rules for expansion:

a. If a pixel $\mathrm{C}$ (current cropland) belongs to Type $\mathrm{HH}$ area and is surrounded by pixels under "tree land" then the 8 immediate adjoin pixels (1s in Figure 5), 16 pixels (2s) immediately surrounding the pixels identified with $1 \mathrm{~s}$, and the 24 pixels (3s) immediately adjacent to the $2 \mathrm{~s}$ are assumed to become cropland in the next five to ten years (i.e. all the $1 \mathrm{~s}, 2 \mathrm{~s}$, and $3 \mathrm{~s}$ are candidates);

b. For HL and $\mathrm{MH}$ areas, cropland expansion is more modest. It only assumes the 8 pixels (1s) immediately adjoining pixel $\mathrm{C}$ and the 16 pixels (identified as $2 \mathrm{~s}$ ) to become cropland in the future if they currently classified as "tree land"; and

c. The expansion is even lower in ML and LH areas as it only considers the 8 pixels immediately adjoining pixel $\mathrm{C}$ in the projected cropland conversion. Finally, we assume that any "tree land" of the Type LL area will not become cropland in the future.

Hence, in the moderate expansion scenario and given that each pixel is roughly about $1 \mathrm{~km}^{2}$, the maximum possible conversion to cropland is $48 \mathrm{~km}^{2}$ in $\mathrm{HH}$ areas, $24 \mathrm{~km}^{2}$ in HL and $\mathrm{MH}$ areas, and $8 \mathrm{~km}^{2}$ in ML and LH areas. However, as current cropland areas are often connected, i.e., many pixels (C) are already adjacent each other, only those $C$ pixels at the boundary areas are considered when their surrounded pixels under "tree land" become candidates for cropland expansion in the scenario.

\begin{tabular}{|l|l|l|l|l|l|l|l|l|l|l|}
\hline 5 & 5 & 5 & 5 & 5 & 5 & 5 & 5 & 5 & 5 & 5 \\
\hline 5 & 4 & 4 & 4 & 4 & 4 & 4 & 4 & 4 & 4 & 5 \\
\hline 5 & 4 & 3 & 3 & 3 & 3 & 3 & 3 & 3 & 4 & 5 \\
\hline 5 & 4 & 3 & 2 & 2 & 2 & 2 & 2 & 3 & 4 & 5 \\
\hline 5 & 4 & 3 & 2 & $\mathbf{1}$ & $\mathbf{1}$ & $\mathbf{1}$ & 2 & 3 & 4 & 5 \\
\hline 5 & 4 & 3 & 2 & $\mathbf{1}$ & $\mathbf{C}$ & $\mathbf{1}$ & 2 & 3 & 4 & 5 \\
\hline 5 & 4 & 3 & 2 & $\mathbf{1}$ & $\mathbf{1}$ & $\mathbf{1}$ & 2 & 3 & 4 & 5 \\
\hline 5 & 4 & 3 & 2 & 2 & 2 & 2 & 2 & 3 & 4 & 5 \\
\hline 5 & 4 & 3 & 3 & 3 & 3 & 3 & 3 & 3 & 4 & 5 \\
\hline 5 & 4 & 4 & 4 & 4 & 4 & 4 & 4 & 4 & 4 & 5 \\
\hline 5 & 5 & 5 & 5 & 5 & 5 & 5 & 5 & 5 & 5 & 5 \\
\hline
\end{tabular}

Source: Authors' illustration.

Figure 1. Illustration of cropland expansion at pixel level

The high expansion scenario (Scenario 2) doubles the cropland expansion in the moderate scenarios in the next five to ten years and is based on the following assumptions:

a. In $\mathrm{HH}$ area, pixels $1,2,3,4$, and 5 surrounding pixel $\mathrm{C}$ are assumed to be converted to cropland if their current land use is characterized under "tree land";

b. Pixels 1,2,3, and 4 surrounding $\mathrm{C}$ in $\mathrm{HL}$ and $\mathrm{MH}$ areas that are currently covered with "tree land" are assumed to be converted to cropland; and 
c. In ML and LH areas, only the pixels 1,2, and 3 are assumed to become cropland if currently part of "tree land" area.

The resulting cropland expansion of both scenarios is presented in Map 4. It should be noted that the precision and accuracy of the potential cropland expansion are hindered by the lack of additional location-specific information and inability to verify the estimates at the ground level. Moreover, realizing the agricultural potential of new cropland depends on many other important factors such as public investments and policies, which can complicate the process and hence are not considered in the projections. Also, additional factors such as access to markets, land and forest policy regulations, as well as access to resources (tools and labor) required for land clearing and tree cutting, will determine the extent the actual extent of expansion.

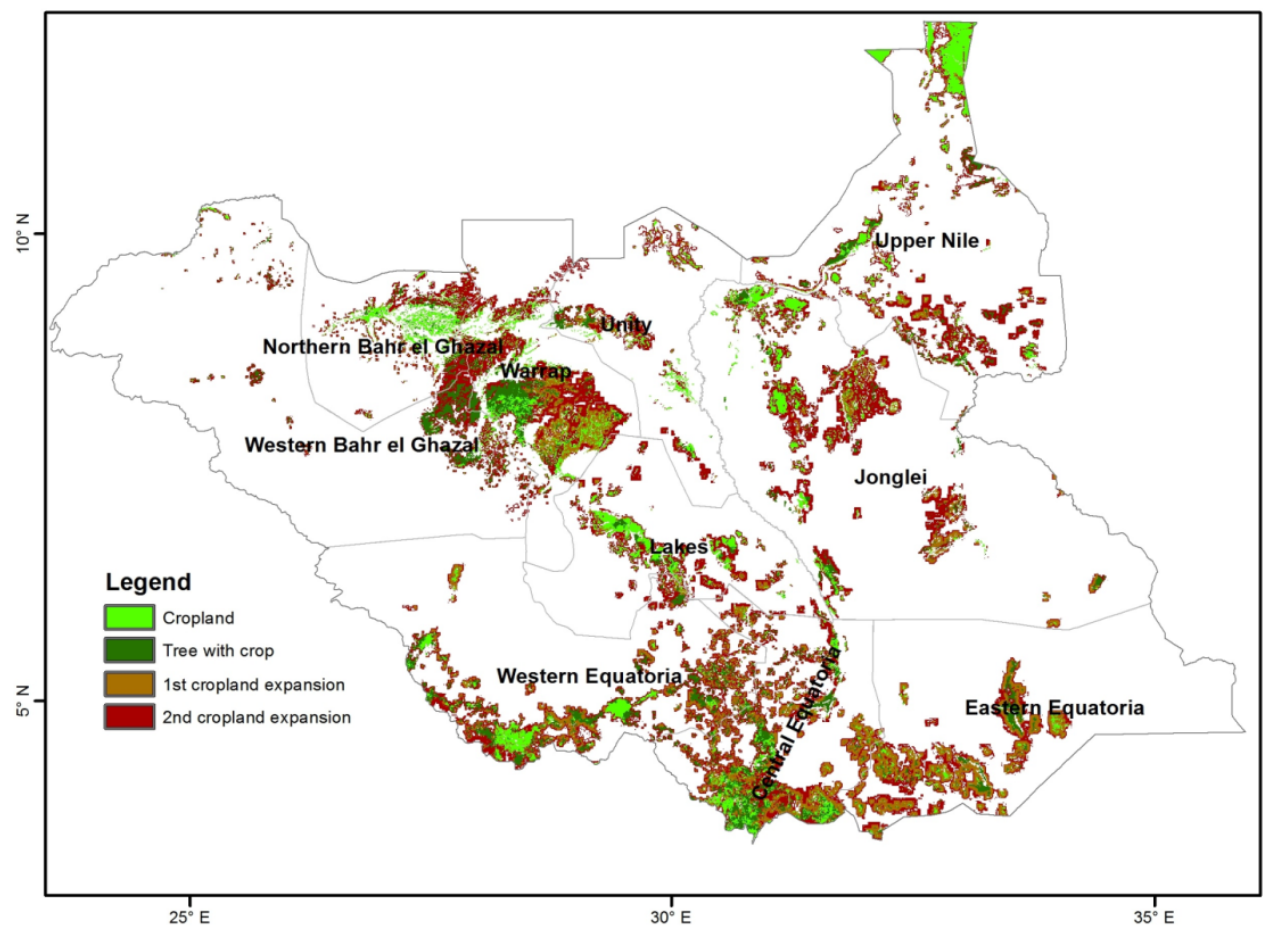

Source: Authors' estimates

Map 4. Cropland expansion under the two scenarios

We focus on the moderate expansion scenario first. Holding other factors constant, cropland area will increase by 2.3 times, from the current 2.7 million ha to 6.3 million ha (Table 3 ). Cropland becomes 9.7 percent of national total land, up from the current (base) of 4.1 percent. While this increase is significant, it is still far below the agricultural potential assessed by the GOSS, which assesses that 50 percent of South Sudan's land surface is prime agricultural land (GOSS 2010). The share of "tree land" in total area will only slightly decline from the current 63 percent to 60 percent (Table 3). 
As expected, most cropland expansion occurred in areas with high agricultural potential. The areas under Type HH, HL, and $\mathrm{MH}$ would collectively expand from the current 53 percent to 65 percent of total cropland area. At the state level, the largest expansion into new crop land is expected in Western Bahr el Ghazal and the three Equatorial states (Map 4). Among the livelihood zones, there is huge potential for crop area expansion in Greenbelt and Western Flood Plains.

We also calculate the change in per capita cropland size under the moderate expansion scenario, assuming a 2.5 percent annual population growth rate. If the expansion occurs in five years, the per capita cropland size will increase from the current national average of 0.32 ha to 0.66 ha. If the expansion would take ten years, the land size will increase to 0.59 ha. In either 5- or 10-year simulation, only Western Bahr el Gazal and Western Equatoria will reach cropland size of at least 1.0 ha per capita.

While the rate of cropland expansion is already rapid in Scenario 1, the per capita cropland would still be lower than in neighboring countries. Hence, we consider Scenario 2 that doubles the rate of expansion under the first scenario. Under this more aggressive scenario, there would be a 3.5-fold increase in cropland area of 9.2 million ha (accounting for 14.3 percent of national land). The share of tree land in total land will decline to 55 percent from the current 63 percent. The per capita cropland area under the high expansion scenario would correspondingly increase to $1.0 \mathrm{ha} / \mathrm{pc}$ if the expansion is achieved in the next five years and $0.87 \mathrm{ha} / \mathrm{pc}$ if expansion takes place in the next 10 years.

\begin{tabular}{lcccccc}
\hline \multirow{2}{*}{ Land use categories } & \multicolumn{2}{c}{ Area (in 1000 ha) } & \multicolumn{3}{c}{ Share of total land (\%) } \\
& Current & Scenario 1 & Scenario 2 & Current & Scenario 1 & Scenario 2 \\
\hline Cropland & $2,680.9$ & $6,267.4$ & $9,237.4$ & 4.1 & 9.7 & 14.3 \\
Trees with crops & $1,536.6$ & 0.0 & 0.0 & 2.4 & 0.0 & 0.0 \\
Tree land & $40,526.9$ & $38,477.1$ & $35,507.1$ & 62.6 & 59.5 & 54.9 \\
Grass with crops & 292.6 & 292.6 & 292.6 & 0.5 & 0.5 & 0.5 \\
Grass & $9,633.8$ & 9.633 .8 & $9,633.8$ & 14.9 & 14.9 & 14.9 \\
Other land use & $10,017.3$ & $10,017.3$ & $10,017.3$ & 15.5 & 15.5 & 15.5 \\
\hline Total & $64,688.3$ & $64,688.3$ & $64,688.3$ & 100.0 & 100.0 & 100.0 \\
\hline
\end{tabular}

Source: Authors' calculations.

Note:

(1) Other land use includes Flood land, Water and rock, and Urban as categorized originally in Table 1.

(2) Cropland under "Current" is the sum of land use under original crop land area (24,779 million ha; see Table 1) plus 10 percent of land use under "grass with crops" and 10 percent of land use under "trees with crops".

Table 3. Land expansions in the two scenarios

The increase in cultivated areas through cropland expansion in both scenarios lead to higher agricultural output, and consequently to higher value of agricultural production. Even under the modest cropland expansion (Scenario 1), the value of total agricultural output (including crops, livestock, and fisheries) becomes 2.4 times higher (about US\$ 2 billion) than the current US $\$ 800$ million. It is expected that the largest increase will come from the three Equatorial states, Western Bahr el Ghazal, and Warrap. In the high expansion 
scenario, the potential agricultural production value reaches US\$2.8 billion but is still far below the level of output produced in neighboring countries.

\section{Yield improvement}

Land expansion is only one of many ways to explore agricultural potential; another avenue is to increase land productivity which also happens to be low in South Sudan. In order to be at par with its neighbors' production levels, yield improvement is necessary. There is a huge gap between the county's actual farm yield and the biophysically achievable yield according to IIASA/FAO Agro-ecological Zone (AEZ) framework (Fischer et al. 2002). The average cereal yield is only about 0.95 ton/ha (FAO/WFP, 2011), but can actually be lower since the cropland area used in the FAO/WFP (2011) is much lower than the areas observed in Land Cover (FAO 2009). This average cereal yield is lower than Uganda where there is minimal use of tradeable inputs (1.6 tons/ha), as well as lower in places with disadvantageous agroecological conditions like Ethiopia ( 3 tons/ha) and Kenya ( 2 tons/ha). Such wide yield gap in South Sudan points to a large opportunity to increase average cereal yields.

We design four yield increase scenarios in which the average yield will increase by 50, 100, 200 , and 300 percent in a period of 5 or 10 years. An increase by 50 percent is simulated to achieve the average level in Uganda, by 100 percent to attain Kenya's level, and by 200 percent to reach that of Ethiopia. While there is no neighboring country with a cereal yield of 6.0 ton/ha national wide (300 percent increase), such level is observed in certain parts of Ethiopia and Kenya.

Under Scenario 1 of land expansion, a 50 percent yield increase would increase the agricultural production value 3.5 times from the current value. This increase in agricultural value is also 45 percent higher than the increase achieved from Scenario 1 without yield improvement. Accordingly, the value of crop production per ha will grow from the current US $\$ 227$ to US $\$ 340$. If yields can increase by 100 percent to mirror the average levels in Kenya, the value of agricultural production in South Sudan (about US $\$ 3.7$ billion) will overtake the current value in Uganda and crop value per ha will be US $\$ 453$. Under the most aggressive scenario, with average yield increasing by 300 percent, the total agricultural value will reach US\$ 7.9 billion and US\$ 1,903/ha.

There are two caveats in our estimation of agricultural potential. First, we do not consider the price effect. At the present, food production of South Sudan is not enough for domestic demand. Urban consumption is primarily met by imports, and food aid is an important food source both for rural and urban households. Thus, we do not expect that a modest increase in crop production to cause an oversupply issue for the country in general. However, it is still possible that significant increases in crop yields, in the absence of opportunities to export surplus can create glut in certain areas during harvest season. When this happens, the prices for many crop products are expected to fall, which indicates that we may overestimate the agricultural potential. The second caveat is related to the livestock sector which we did not consider in the supply increase simulation although this sector also has a huge potential in the country. Without considering productivity increase in livestock production, we may significantly underestimate the agricultural potential. 


\section{Conclusion}

South Sudan, the world's newest nation, has a huge agricultural potential that can be leveraged to improve the national economy and household living standards. The country's endowment of favorable land, water, and weather conditions makes 70 percent of land suitable for agriculture. Yet, less than four percent of total land (about 2.7 million ha) is currently cultivated while more than 80 percent is still under natural vegetation (e.g. trees, shrubs, grass). The production system remains primarily subsistence in nature and crop yield is low. Our analysis shows that the current total value of agriculture production (i.e. "realized potential") only amounts to about US\$800 million (US\$ 600 million from crops) or less than US $\$ 300$ per hectare, which is much lower than that of its neighbouring countries. Even with an extremely low population density ( 13 persons per $\left.\mathrm{km}^{2}\right)$, per capita crop area is only at 0.3 hectare.

In this context, the newly independent country faces challenges in providing enough food for her population that is expected to increase in the short run due to the re-integration of displaced people. Obstacles in developing the country's competitiveness in regional and global markets in the longer term also need to be overcome. In order to have a more realistic agricultural development strategy and investment priorities, it is necessary to understand the country's current agricultural situation and potential for improvement in the near future. We employ a GIS-based analysis and come up with six agricultural potential typologies. $\mathrm{HH}, \mathrm{HL}$, and $\mathrm{MH}$ are best positioned to be developed, and more than half of current cropland areas fall under these categories. There is possibility of promoting intensive farming systems since areas with "high" and "medium" agricultural potential have population density greater than the $50 / \mathrm{km}^{2}$ threshold. However, there are also "high" agro-ecological potential areas with very low population density indicating the difficulty to develop them with a smallholder farming system.

Incorporating these elements together, we then spatially estimate the agricultural potential value in the next five to ten years by simulating: (1) an increase in cultivated area though cropland expansion, and (2) crop yield improvement. If cropland areas expand to 6.3 million or 9.2 million hectares, size of per capita land holding will significantly increase, and consequently results in higher value of agricultural production relative to the current "realized potential". However, the potential agricultural value even in the high expansion scenario is still far below the level of output produced in neighboring countries.

Catching up with crop yield levels achieved by its neighboring countries will be the most important approach to realize agricultural potential. Doubling the current average cereal yield of 0.95 ton/ha, along with moderate cropland expansion, will shoot up the value of agricultural production to US\$3.7 billion, a level that can overtake the current agricultural value in Uganda. Given that many challenges in cropland expansion, including high upfront costs of land clearing and low rural connectivity, yield improvement maybe a more effective way to realize agricultural potential in South Sudan over the next years. 


\section{Author details}

Xinshen Diao, Liangzhi You, Vida Alpuerto and Renato Folledo

International Food Policy Research Institute (IFPRI), Washington DC, USA

\section{Acknowledgement}

The chapter is the primary research output of a project funded by Africa Region of the World Bank. Tremendous support has been received from the government of South Sudan, WFP and FAO Sudan offices, researchers in many institutions/organizations in the country, and the World Bank South Sudan office. The principal authors accept responsibility for any errors.

\section{References}

FAO, 2009. FAO Livestock Population Estimates, Oct 2009. FAOStat, Aug 2010

FAO, 1981. Report of the Agro-Ecological Zones Project, World Soil Resources Report No 48, Vol.1-4, Rome, FAO

FAO/WFP. 2009. FAO/WFP crop and food security assessment mission to Southern Sudan, Special Report, 2008/2009, http://www.fao.org/giews.

FAO/WFP. 2010. FAO/WFP crop and food security assessment mission to Southern Sudan, Special Report, 2009/2010, http://www.fao.org/giews.

FAO/WFP. 2011. FAO/WFP crop and food security assessment mission to Southern Sudan, Special Report, 2010/2011, http://www.fao.org/giews.

Fischer, G., H.T. van Velthuizen, and F.O. Nachtergaele. 2002. Global agroecological assessment for agriculture in the 21st century: Methodology and results. RR-02-02. Laxenburg, Austria: International Institute for Applied System Analysis.

GOSS. 2010. The Southern Sudan Food and Agriculture Policy Framework.

Guvele, Cesar. 2009. Agricultural situation in Southern Sudan and the potential for development: a review. A report submitted to USAID.

LandScan, 2008. http://www.ornl.gov/sci/landscan/index.shtml (accessed November 2010).

Musinga, M., J.M. Gathuma, O. Engorok, and T. H. Dargie. 2010 The Livestock Sector in Southern Sudan: Results of a Value Chain Study of the Livestock Sector in Five States of Southern Sudan Covered by MDTF with a Focus on Red Meat. The Netherlands Development Organization.

Southern Sudan Centre for Census, Statistics and Evaluation (SSCCSE). 2010. Poverty in Southern Sudan: Estimates from the NBHS 2009. Juba: SSCCSE.

Southern Sudan Centre for Census, Statistics and Evaluation (SSCCSE), Save the Children UK (SC UK), USAID Famine Early Warning Systems Network (FEWS NET). 2006. Southern Sudan Livelihood Profiles. January 2006.

Uchida, Hirotsugu, and Andrew Nelson. 2008. Agglomeration index: towards a new measure of urban concentration. Background paper for the WDR 2009.

World Food Program (WFP) and The Ministry of Transport and Roads, Government of Southern Sudan (GOSS). 2005. WFP Southern Sudan Emergency Road Rehabilitation Program - Socio-economic impact assessment: A report of 2004 and 2005 road rehabilitation activities 